\title{
Small bowel enteroscopy in undiagnosed gastrointestinal blood loss
}

\author{
A J Morris, L A Wasson, J F MacKenzie
}

\begin{abstract}
Sixty five of 70 consecutive patients with undiagnosed gastrointestinal blood loss were examined using the new technique of small bowel enteroscopy. Using a balloon driven sonde enteroscope (SIF-SW) extended views of the small bowel were obtained as far as the distal ileum. Medium length of small bowel examined was $140 \mathrm{~cm}$ (range $(30-200 \mathrm{~cm}$ ). All patients studied had a normal upper gastrointestinal endoscopy. Nineteen (41\%) of 46 anaemic rheumatoid arthritis patients taking non-steroidal antiinflammatory drugs (NSAID) and three (27\%) of 11 patients with unexplained iron deficiency, were found to have small bowel lesions to account for their anaemia. Small bowel lesions were found in a further three of eight (37\%) patients with acute gastrointestinal bleeding. The procedure failed or was terminated in five patients. Small bowel enteroscopy has considerable potential in the investigation of undiagnosed gastrointestinal blood loss and deserves more widespread application.
\end{abstract}

In patients with gastrointestinal blood loss and normal upper and lower gastrointestinal tracts the small bowel is a potential site of bleeding. Until recently, attempts to examine the small bowel endoscopically have been limited by the use of suboptimal instruments and techniques. In the past, a limited length of proximal small bowel could be examined using a paediatric colonoscope' or a 'push' enteroscope passed orally and advanced under direct vision beyond the duodenal loop. ${ }^{2}$ These procedures offer limited small bowel views because of the increasing difficulty as the endoscope enters unsupported jejunum beyond the ligament of Treitz, although this may be improved by the use of an overtube. ${ }^{3}$ With the development of a balloon driven 'sonde' enteroscope, even more extended views of the small bowel can now be obtained. ${ }^{4}$ Using this new technique, Lewis and Waye have found small bowel lesions in $33 \%$ of patients with gastrointestinal bleeding of obscure origin. ${ }^{5}$

We have used a similar prototype sonde enteroscope (Olympus SIF-SW) and with the

TABLE I Patient details

\begin{tabular}{lllll}
\hline Group & $\begin{array}{l}\text { Patients } \\
\text { examined }(n)\end{array}$ & $\begin{array}{l}\text { Age: } y r \\
\text { Median (range) }\end{array}$ & Sex M:F & $\begin{array}{l}\text { Haemoglobin g/dl } \\
\text { Median }(\text { Range) }\end{array}$ \\
\hline I & 46 & $60(27-77)$ & $10: 36$ & $8 \cdot 9(6 \cdot 9-12 \cdot 0)$ \\
II & 11 & $65(27-77)$ & $4: 7$ & $9 \cdot 7(5 \cdot 8-11 \cdot 3)$ \\
III & 8 & $67(23-79)$ & $3: 5$ & $8 \cdot 1(5 \cdot 5-9 \cdot 1)$ \\
\hline
\end{tabular}

modified technique of water insufflation have studied 70 consecutive patients with undiagnosed chronic and acute gastrointestinal blood loss.

\section{Methods}

\section{PATIENTS}

The 70 patients examined were in three groups; (i) rheumatoid arthritis patients taking nonsteroidal antiinflammatory drugs and proven iron deficiency anaemia (group I): (ii) recurrent iron deficiency anaemia of unknown cause (group II) and (iii) acute gastrointestinal bleeding (group III). Before entry to the study patients had a normal upper gastrointestinal endoscopy. In all patients alternative sites of blood loss either urinary or menstrual were excluded. Patients in group II were not taking a salicylate or a nonsteroidal antiinflammatory drug. Table I gives patient details for each group.

SMALL BOWEL ENTEROSCOPY

Small bowel examination was carried out using a prototype balloon driven (sonde type) fibreoptic enteroscope $2.7 \mathrm{~m}$ in length and $0.5 \mathrm{~mm}$ in diameter (Olympus SIF-SW). The enteroscope was passed nasally into the stomach. A second upper gastrointestinal pan endoscope (GIFXQ-20) was then passed orally as for normal upper gastrointestinal endoscopy. With both instruments in the stomach biopsy forceps passed through the panendoscope were used to snare a silk suture on the tip of the enteroscope and guide the enteroscope through the pylorus into the duodenum under direct vision. A balloon surrounding the distal $4 \mathrm{~cm}$ of the enteroscope was then inflated and the panendoscope withdrawn. Subsequent progress down the small intestine was mediated by the propulsive effect of small bowel contractions. Small lengths were introduced hourly and progress of the enteroscope was monitored using radiographic screening. The procedure was deemed complete when the enteroscope had advanced its entire length or when it failed to advance between consecutive radiographic screening separated by one hour.

Direct visualisation of the mucosa was obtained during withdrawal of the enteroscope. We have introduced the technique of water insufflation during the visualisation phase of this procedure. Using a pressure pump, saline was infused through the instrument tip at $20 \mathrm{ml} /$ minute. Control of the tip of the instrument was enhanced by means of a compressible air reservoir connected to the balloon at the tip of the enteroscope. Improved control of tip position was achieved by direct foot control of the external 
TABLE II Enteroscopy findings

\begin{tabular}{llll}
\hline Group & $\begin{array}{l}\text { Distance enteroscope } \\
\text { advanced Median (range) } \\
\mathrm{cm}\end{array}$ & $\begin{array}{l}\text { Small bowel lesions } \\
\text { Patients }(n)\end{array}$ & $\begin{array}{l}\text { Lesions to account for } \\
\text { anaemia }(\%)\end{array}$ \\
\hline I & $190(90-250)$ & $\begin{array}{l}7 \text { red spot lesions only } \\
6 \text { erosions }\end{array}$ & 19 of $46(39 \%)^{\star}$ \\
II & $200(110-250)$ & $\begin{array}{l}13 \text { ulcers } \\
\text { angiodysplasia }\end{array}$ & 3 of $11(27 \%)$ \\
III & $220(190-260)$ & 3 ulcer & 3 of $8(37 \%)$ \\
\hline
\end{tabular}

* Only erosions and ulcers in Group I considered to cause anaemia.

air resevoir. Further enhancement of luminal views was obtained by abdominal palpation. Lesions were documented by two observers (JM, JFMack) and either photographed or recorded on video for subsequent viewing by both observers.

\section{SMALL BOWEL LESIONS (DEFINITION)}

\section{1: Red spot lesion}

Demarcated, usually circular 1-3 mm area of crimson mucosa with preservation of overlying villi.

\section{2: Erosions}

Distinguished from (1) by clear loss of villi across area of lesion, $<5 \mathrm{~mm}$ diameter with defined edge to lesion.

\section{3: Ulcers}

Penetrating lesion of bowel mucosa with diameter $>5 \mathrm{~mm}$.

\section{Results}

Examination of the small bowel was successful in 65 of $70(92 \%)$ patients in whom it was attempted. The procedure took a median of six hours (range $4 \cdot 5-7 \cdot 5$ hours) to complete. The median length of small bowel examined was estimated by subtracting $60 \mathrm{~cm}$ from the distance that the enteroscope advanced, this length being the distance between the nares and the pylorus. The median length of small bowel examined for all groups was $140 \mathrm{~cm}$ (range $30-200 \mathrm{~cm}$ ). Abnormalities of the small bowel were found in a total of $32(49 \%)$ patients examined. Table II gives the details of the distance the enteroscope travelled through the small bowel and result of abnormalities observed in each group. In some patients red spots and ulceration coexisted. In this case only the more severe lesions were recorded.

The procedure failed or was terminated in five patients all of whom were in group I. In one patient the instrument could not be passed through the nose and in a further two, the balloon tip burst after passing into the duodenum and the instrument failed to migrate distally into the small bowel. In two of the patients, perforation of the small bowel occurred during enteroscopy. In the first patient the instrument perforated a large small bowel ulcer and in the second, accidental over dilatation of the distal balloon caused traumatic small bowel perforation. In both patients early diagnosis of the perforation was made leading to laparotomy and small bowel resection with uncomplicated postoperative recovery.

\section{Discussion}

The development of a long, highly flexible fibreoptic endoscope means that the small bowel can now be examined potentially as far as the terminal ileum. In this paper we have shown small bowel lesions to account for anaemia in 25 $(38 \%)$ of the 65 patients examined. These lesions had not been identified by standard methods of investigation. Our finding of mucosal abnormalities in $56 \%$ of patients in group I is consistent with previous radioisotope studies suggesting the small bowel is a major site of gastrointestinal damage in patients taking long-term NSAID. ${ }^{\circ}$ The red spot lesions were unlikely to be the source of blood loss but we felt probably represented the earliest mucosal lesion which may develop into erosion or ulcers. The frequency of lesions causing anaemia in this group was therefore $39 \%$ compared with $27 \%$ in those patients in group II not on NSAID. In the patients in group II the observed frequency of abnormalities is closely similar to that of a previous study. ${ }^{5}$ In group III we found three patients with small bowel ulcers one of which was actively bleeding at the time of the examination. Two of these patients were taking aspirin regularly and we suspect aspirin may have caused the lesions. Drug induced small bowel ulceration may be more common than previous case reports would suggest. ${ }^{78}$ The prevalence of these lesions in acute gastrointestinal haemorrhage can only be found by more widespread use of enteroscopy in these circumstances.

The major limitation of small bowel enteroscopy is that tip deflection and biopsy facility have been sacrificed to reduce the outer diameter of the instrument and enhance flexibility. In our experience a further draw back is the failure to visualise $20-30 \%$ of bowel, principally on the inner aspect of curves, traversed but not seen.

We have sought to improve the quality of examination by modification of the technique described by Lewis and Waye. ${ }^{4}$ First, we did not use glucagon to inhibit small bowel contractions. This allowed the enteroscope to be propelled back down the bowel for a few centimetres in response to balloon inflation. Immediate forward movement of the tip allowed reexamination of lesions viewed transiently. This balloon inflation by a controlled reservoir connected to the balloon at the tip allowed fine control of tip deflection while freeing one or both hands for abdominal palpation to maximise liminal views obtained. Second, water insufflation by continuous pump enhances views obtained by inflating the bowel lumen and cleaning luminal debris. Views through clear fluid markedly improved the mucosal detail. In order to limit discomfort to the patient we did not attempt push enteroscopy of proximal duodenum while positioning the sonde enteroscope. This reduced the time spent during introduction of the enteroscope although may have caused some proximal lesions to be missed which may otherwise have been identified by push enteroscopy. 
Despite the length of the procedure, patients tolerated it very well, a fact that may reflect the passive nature of the technique. Some patients experienced minor discomfort during withdrawal of the enteroscope, but this has been alleviated by the use of topical anaesthesia as required. The nose bleeding described by others ${ }^{5}$ was not a problem in our patients.

In our study we had two patients who experienced small bowel perforation. In one of these patients the perforation was a direct result of over distension of the distal balloon caused by an error in channel identification. We have now altered the channel connections to prevent this occurring again.

The possibility has recently been raised that some of the small bowel lesions initially reported by us $^{9}$ may have been enteroscope induced. ${ }^{10}$ Red spot lesions were observed only in those patients taking non-steroidal antiinflammatory drugs. Unlike the traumatic 'suction-bleb' created by inexperienced endoscopists these red spots were seen to underlie villi which were clearly seen and normal. As these lesions were not seen in other types of patient, anci the procedure was similar in both groups, we do not believe they were caused by instrumental trauma. Erosions and ulcers were often multiple and not confined to valvuli conniventes, which would be the potential site of maximal instrumental trauma.

Further improvements are needed to increase the percentage of bowel examined with this instrument. The principal drawback of the instrument being the absence of a mechanism to control tip flexion. Control wires would inevitably stiffen the instrument and may compromise its flexibility. As this flexibility is the key to success in reaching the distal small intestine an alternative mechanism for tip flexion is probably needed. Nevertheless, this particular instrument has revealed sources of blood loss not otherwise accessible to standard diagnostic techniques. We feel that small bowel enteroscopy has considerable potential in the investigation of undiagnosed gastrointestinal blood loss.

We gratefully acknowledge the assistance given to us by Keymed who supplied the enteroscope and other essential equipment to enable the study to be performed.

1 Parker H, Agayoff J. Enteroscopy and small bowel biopsy utilising a peroral colonoscope Gastrointest Endosc 1983; 29: $139-40$.

2 Ogoshi K, Hara Y, Ashizawa. New technique for small intestinal fibreoscopy. Gastrointest Endosc 1973; 20: 64-5.

3 Zuccaro G, Barthel JS, Sivak MV. Use of $165 \mathrm{cms}$ Push Enteroscope in the evaluation of GI bleeding of unknown etiolos. Gastrointest Endosc 1991; 37: A274.

4 Lewis B, Waye J. Total small bowel enteroscopy. Gastrointest Endosc 1987; 33: 435-8.

5 Lewis B, Waye J. Gastrointestinal bleeding of obscure origin: the role of small bowel enteroscopy. Gastroenterology 1988; 94: 1117-20.

6 Bjarnason I. Non-steroidal antiinflammatory drug induced small intestinal inflammation in man. In: Pounder RE, ed. Recent advances in gastroenterology. Edinburgh: Churchill Livinstone, 1988; 23-47.

7 Day TK. Intestinal perforation associated with osmotic clow release indomethacin capsules. $B M \mathcal{F} 1983 ; 287$ : 1671-72.

8 Madhok R, MacKenzie JF, Lee FD, Bruchner FE, Terry TR, Sturrock RD. Small bowel ulceration in patients receiving non-steroidal antiinflammatory drugs for rheumatoid arthritis. Qf Med 1986; 255: 53-8.

9 Morris AJ, Madhok R, Sturrock RD, Capell HA, MacKenzie JF. Enteroscopic diagnosis of small bowel ulceration in patients receiving non-steroidal antiinflammatory drugs. patients receiving not $1991 ; 337: 520$.

10 Lewis B. Small bowel enteroscopy Lancet 1991: 337-1093. 